\title{
THE INFLUENCE OF SEWAGE SLUDGE ON NORWAY SPRUCE (PICEA ABIES (L.) H. KARST.) SEEDLINGS GROWTH
}

\author{
Martynas KEMESIUS, Forester, Utena State Forest Enterprise, Moletu g. 51, Utena, LT-28135, Lithuania, \\ martynas.kemesius@gmail.com \\ Gerda SILINGIENE, Faculty of Forest Sciences and Ecology, Aleksandras Stulginskis University, Studentu g. 11, \\ Akademija, LT-53361, Kaunas raj., Lithuania, gerda.silingiene@asu.lt (corresponding author) \\ Regina VASINAUSKIENE, Faculty of Forest Sciences and Ecology, Aleksandras Stulginskis University, Studentu g. 11, \\ Akademija, LT-53361, Kaunas raj., Lithuania, regina.vasinauskiene@ asu.lt \\ Remigijus ZALKAUSKAS, Faculty of Forest Sciences and Ecology, Aleksandras Stulginskis University, Studentu g. 11, \\ Akademija, LT-53361, Kaunas raj., Lithuania, remigijus.zalkauskas@asu.lt
}

The usage of biodegradable waste as sewage sludge in a proper way for tree nurseries enable to seek for ecological, waste-less, alternative to mineral fertilization farming ways. The aim of this research is to investigate impact of sewage sludge fertilizers on Norway spruce (Picea abies) two years' seedlings growth. Research has been done in 2013-2014 at Utena State Forest Enterprise nursery. The different fertilization rates $(20,40,60,80,100 \mathrm{t} / \mathrm{ha})$ of sewage sludge were investigated and compared with control - traditional fertilization with mineral fertilizers. The impact of sewage sludge was evaluated by seedlings biometric indicators, also dry mass of sample seedlings (medium seedlings by height and diameter). The bigger rates of sewage sludge showed almost better results in exception of seeds outlet. Sewage sludge has long lasting effect on seedlings growth and could successfully shift soil fertilization by mineral fertilizers. The obtained research results confirm the similar research carried out in 2011 in Rokiskis State Forest Enterprise nursery for first year Norway Spruce seedlings.

Keywords: mineral fertilizer, Norway spruce seedlings, sewage sludge.

\section{INTRODUCTION}

Due to the society concern about ecological, waste-less farming way, quite expansive mineral fertilisers direct researchers for search of new, less expensive local materials, instead of mineral fertilizes, while growing forest tree seedlings at tree nurseries. Beside the traditional organic fertilizers, the use of biodegradable waste, as sewage sludge, is started. The use of sewage sludge for fertilization is more common for agricultural crops. For example, in Finland $31 \%$ of sewage sludge is used for fertilization of fields, $17 \%$ - urban greenings, $33 \%$ - roadside greenings and flowerings (Janeliauskiene, 1998). The sewage sludge started to use for forest fertilization since 1980 in USA (Gradeckas et ct, 1995). From other side, the promotion of trees growth by sewage sludge and wastewater application can deteriorate water quality - carefull managed is needed (Osman, 2013). The studies are needed to determine the heavy metals behavior in soil-plant continuum on long term with the assessment of their transfer to groundwater and all along the food chain - the sewage sludge is considered to be a source of fertilizer due to the high content of plant's available N, P, and organic matter, but no significant promoting of above- and belowground plant part growth in seedlings is observed in short term (several weeks perriod) (Bourioug et al, 2014). Despite the ongoing research in the usage of sewage sludge there is still luck of recommendations of the rates of sewage sludge for forest tree nurseries. According to State Forest Survey data the area of 38 tree nurseries of state forest enterprises occupy 1249 ha, $60 \%$ of seedlings production goes for Norway Spruce seedlings (Lithuanian Statistical ..., 2014).

The aim of this paper was to explore the influence of sewage sludge of different rates on Norway Spruce two years seedlings growth. The influence was evaluated by responding biometric characteristics of Norway Spruce two years seedlings. The similar research was carried out in 2011 in Rokiskis State Forest Enterprise nursery while evaluating the impact of sewage sludge fertilization on first year Norway Spruce seedlings (Racinskas, 2013). By applying the same methodology, the research was repeated at Utena State Forest Enterprise nursery while evaluating the two years seedlings taking in mind what the sewage sludge may have long lasting impact.

Copyright (C) 2015 The Authors. Published by Aleksandras Stulginskis University. This is an open-access article distributed under the terms of the Creative Commons Attribution License (CC-BY 4.0), which permits unrestricted use, distribution, and reproduction in any medium, provided the original author and source are credited. 


\section{RESEARCH METHODS}

The research of this paper was carried out in 2013-2014 at tree nursery of Utena state forest enterprise. Research plots of $3 \mathrm{~m}^{2}$ of all fertilization scenarios were repeated by 3 time. Experiment was carried out on Hapli-Albic Arenosols soils. 6 fertilization scenarios were taken in account:

1.The soil was fertilized just by mineral fertilizers (each year) - Control;

2.The soil was fertilized by sewage sludge once by rate (SS20) - 20 t/ha;

3.The soil was fertilized by sewage sludge once by rate (SS40) - $40 \mathrm{t} / \mathrm{ha}$;

4.The soil was fertilized by sewage sludge once by rate (SS60) - $60 \mathrm{t} / \mathrm{ha}$;

5 .The soil was fertilized by sewage sludge once by rate (SS80) $-80 \mathrm{t} / \mathrm{ha}$;

6.The soil was fertilized by sewage sludge once by rate (SS100) - $100 \mathrm{t} / \mathrm{ha}$.

The soil preparation, sowing, maintenance were carried out by spruce seedlings cultivation technology (Skov, 1996). Seeds were stained by fungicide „Maxim $025 \mathrm{FS}$ ” (20 ml of stain and 20-30 ml of water per $10 \mathrm{~kg}$ of seeds). The first class Norway spruce seeds were sown on 18 of May 2013 by scheme (25-25-25-25-70) while applying $10 \mathrm{~g}$ seeds for $1 \mathrm{~m}^{2}$.

The sewage sludge was spread once before sowing. Before sowing Control scenarios soil were fertilised by „YaraMila COMPLEX“ $\mathrm{N}_{12} \mathrm{P}_{11} \mathrm{~K}_{18}+\mathrm{Mg}+\mathrm{S}+\mathrm{B}+\mathrm{Fe}+\mathrm{Mn}+\mathrm{Zn}$ (230 kg/ha). During additional fertilization in the first year, the Sal saltpetre were applied for Control scenarios (first decade of June $-270 \mathrm{~kg} / \mathrm{ha}$, third decade of June $-270 \mathrm{~kg} / \mathrm{ha}$, third decade of July $-200 \mathrm{~kg} / \mathrm{ha}$ ), as well the complex fertilizer was applied $-\mathrm{N}_{12} \mathrm{P}_{11} \mathrm{~K}_{18}+\mathrm{Mg}+\mathrm{S}+\mathrm{B}+\mathrm{Fe}+\mathrm{Mn}+\mathrm{Zn}$ (third decade of August $-270 \mathrm{~kg} / \mathrm{ha}$ ). In the first year weeds in all scenarios were removed 3 times by hand and 7 times by cultivating the interlines.

Second years seedlings were fertilized in control scenarios by Sal saltpetre (second and third decades of May, second decade of June $-270 \mathrm{~kg} / \mathrm{ha}$ ) and additionally fertilized by complex fertilize $\mathrm{N}_{12} \mathrm{P}_{11} \mathrm{~K}_{18}+\mathrm{Mg}+\mathrm{S}+\mathrm{B}+\mathrm{Fe}+\mathrm{Mn}+\mathrm{Zn}$ $(200 \mathrm{~kg} / \mathrm{ha})$ in second decade of July and August. Weeds were removed 2 times by hand and 8 times by cultivating the interlines in the second year.

The sewage sludge of Utena city is classified as 2 category and B class and can be applied for soils fertilization.

After vegetation 150 sample seedlings were taken from each scenario from mediate density seedlings rows by digging in $25 \mathrm{~cm}$ deep. In total 900 sample seedlings were measured. The dry weight of seedling was evaluated for each fertilization scenarios by drying 30 moderate (according to average of seedlings height and root neck diameter) sample seedlings. The sample seedlings were dried for 20 days in ventilated surrounding and were weighted by electronic weighting machine „KERN eg““

\section{RESEARCH RESULTS}

Biometric characteristics of seedlings (height, diameter of roof neck, length of main root, biomass ect.) reflect the soil nourishment (Slapakauskas, 2006). Just the fertilization by sewage sludge (SS) rate - 100 t/ha (scenarios - SS100) shows higher impact of sewage sludge fertilization on seedlings height- the height was $14 \%$ higher than Control Scenarios (Figure 1).

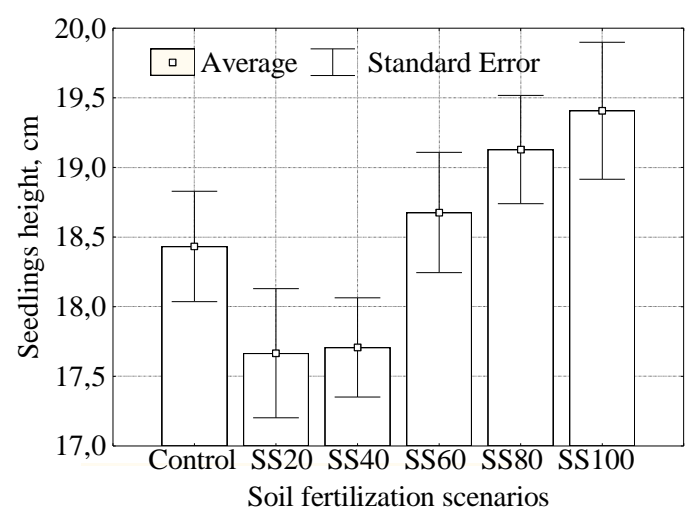

Figure 1. The impact of sewage sludge on Norway spruce two years seedlings height

The height increment of second year seedlings have persistence influence for growth after 1 year of SS spreading. The Control and SS100 scenarios showed the same results (Figure 2).

The diameter of root neck has influence on seedlings quality (Racinskas, 2008). If compare with fertilization by mineral fertilizers, the fertilization by SS with rate 80 t/ha coursed $33 \%$ higher diameter of second year seedlings root neck (Figure 3).

The number of side-on sprouts indicates the seedlings vitality in second and other year's indicator (Racinskas, 2008). While increasing of SS fertilization rate the number of side-on sprouts increase (Figure 4). Fertilization Scenarios SS100 showed $6 \%$ higher number of side-on sprouts. 


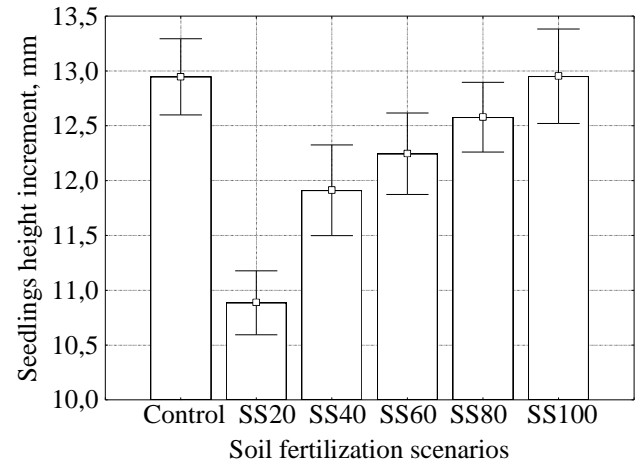

Figure 2. The impact of sewage sludge on Norway Spruce two years seedlings height increment

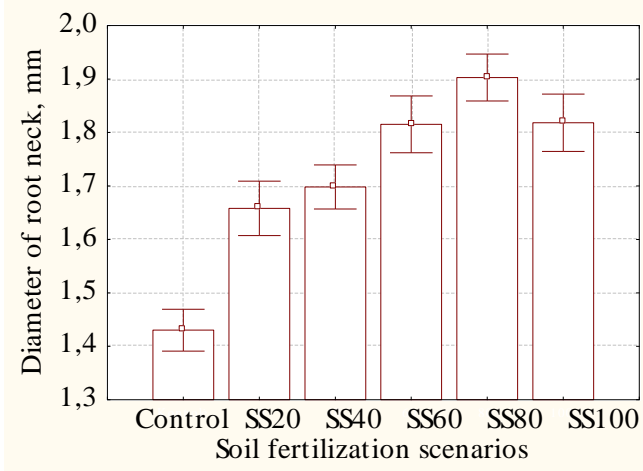

Figure 3. The impact of sewage sludge on Norway Spruce two years seedlings root neck diameter

Needles number and their length are used for plant assimilation set evaluation (Racinskas et al., 2013). The highest benefit for seedlings assimilation set was reached by fertilizing by $100 \mathrm{t} /$ ha of SS what increased the length of needles by $9 \%$ if compare to fertilization by mineral fertilizers (Figure 5).

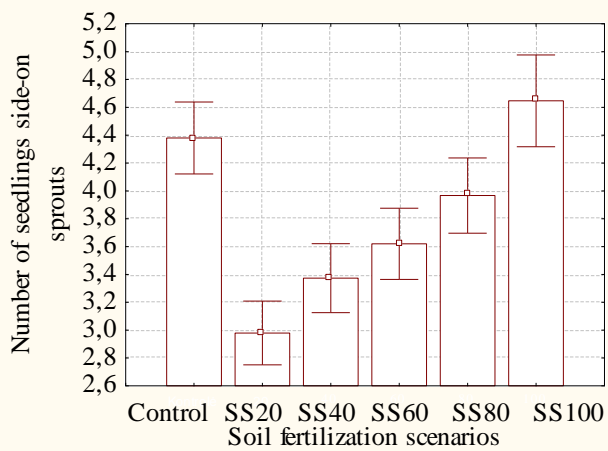

Figure 4. The impact of sewage sludge on Norway Spruce two years seedlings side-on sprouts number

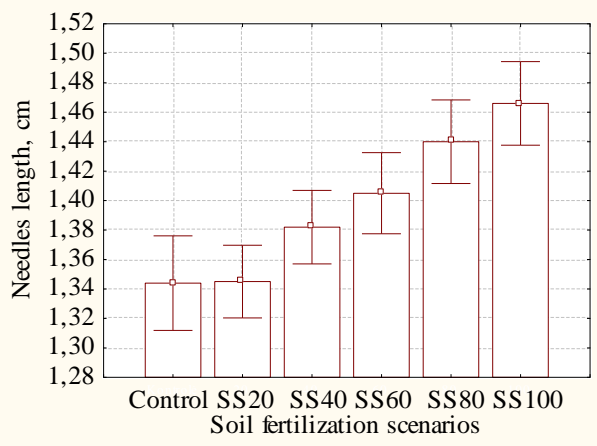

Figure 5. The impact of sewage sludge on Norway Spruce two years seedlings needles length

Soil physical conditions and nutrition distribution in the soil play important role for plants root system development (Kucinskas et al, 1999). Just SS with rate 80 t/ha and 100 t/ha determined almost the same main root length as in Control Scenarios (Figure 6). The first series root length is an important indicator showing the plant capacity to grab nutrition. Just higher rate slightly forced higher length of first series roots height (Figure 7).

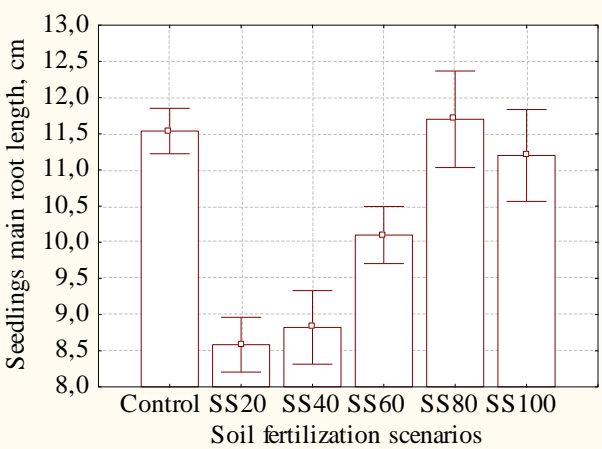

Figure 6. The impact of sewage sludge on Norway Spruce two years seedlings main root length

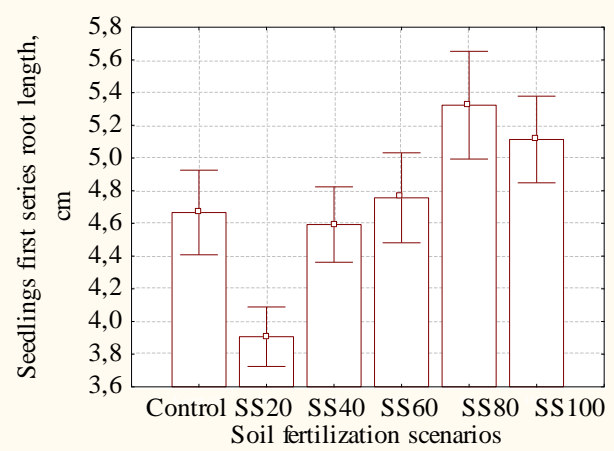

Figure 7. The impact of sewage sludge on Norway Spruce two years seedlings first series root length

Plant total air dry mass indicates the level of plant nourishment (Slapakauskas, 2006). The SS impact on seedlings growth more obvious for second year seedlings (Figure 8). The SS should to mineralize what's why the positive effect becomes more obvious just during the second year growing.

If compare to Control scenarios, the lower seeds germination and seedlings survival belongs to higher concentration of SS soil fertilization scenarios (Figure 9). The lower seeds establishment was coursed due to later seeds germination because of thick SS layer what disturbed to stand slender seeds sprouts. 


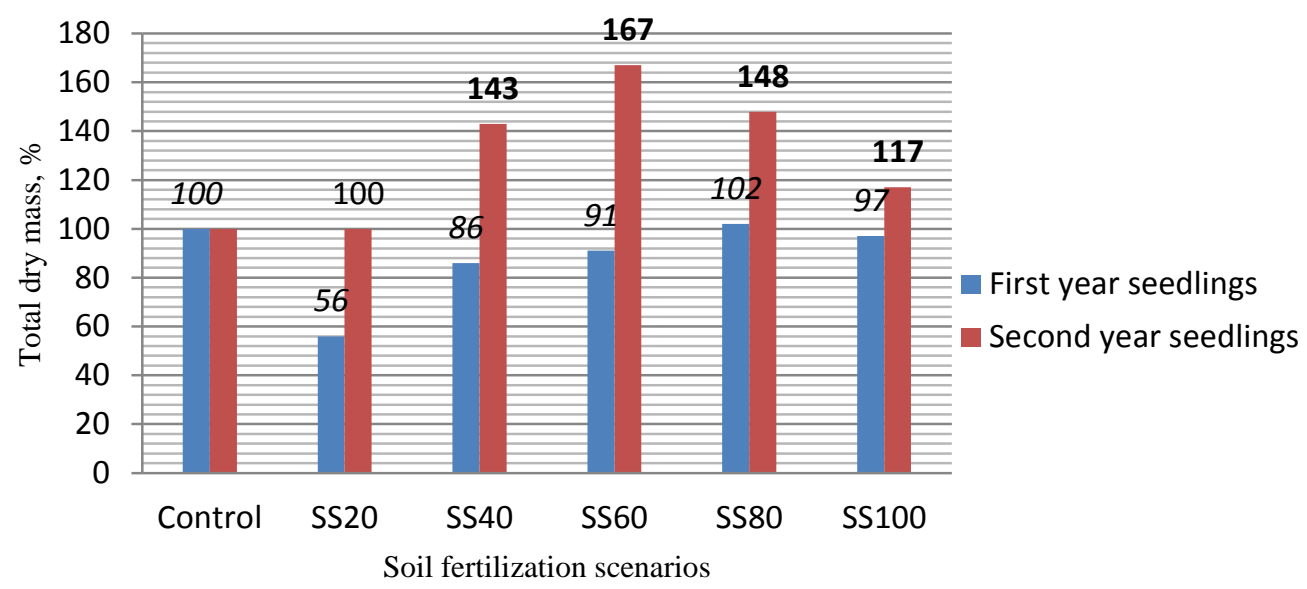

Figure 8. The impact of sewage sludge on Norway spruce seedlings (A - first year; B - second year) total air dry mass

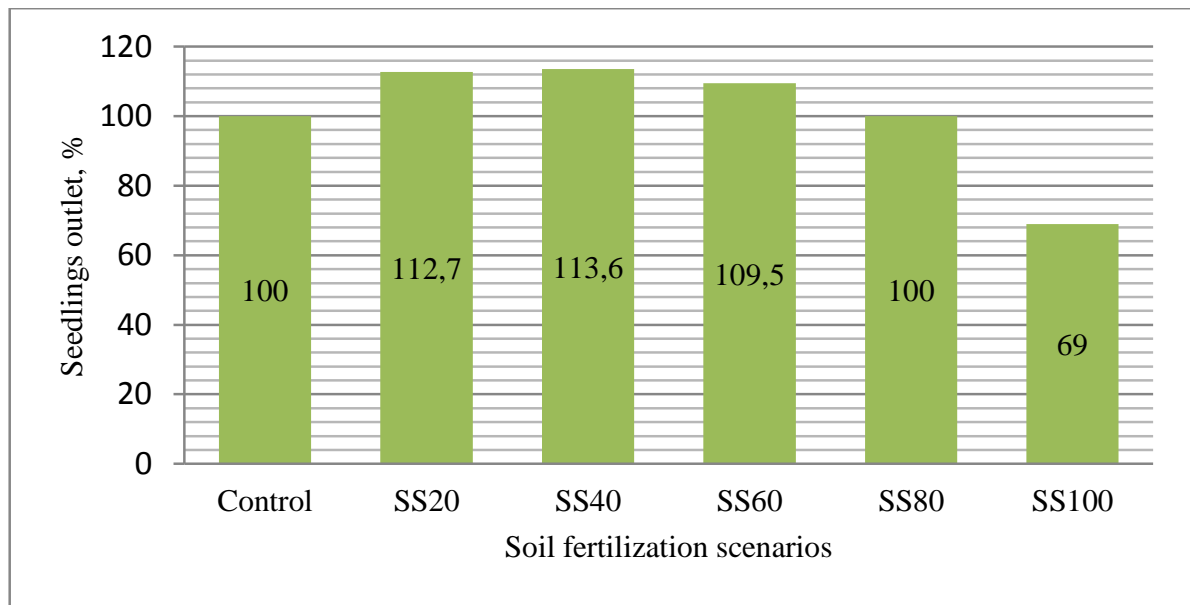

Figure 9. The impact of sewage sludge on Norway spruce seeds germination and seedlings survival after second growing year

\section{CONCLUSIONS AND DISCUSSIONS}

The application of higher rate (80-100 t/ha) sewage sludge for soil fertilization do not worsen for Norway spruce seedlings growth, even slightly increased biometrical data of second year seedlings when comparing with fertilization by mineral fertilizers. Besides the fertilization by sewage sludge was applied just once before sowing while mineral fertilizers were inserted five times during two years. This led to the recommendations to apply sewage sludge for soil fertilization with rate of 80-100 t/ha for changing expensive mineral fertilizers and reducing the costs of Norway spruce seedlings growth in tree nurseries. The obtained research results are similar to research carried out in 2011 in Rokiskis State Forest Enterprise nursery for first year seedlings (Racinskas et al, 2013).

\section{REFERENCES}

1. Bourioug, M., Alaoui-Sossé, L., Laffray X., Raouf N., Benbrahim, M., Badot, P., M., Alaoui-Sossé, B. 2014. Evaluation of Sewage Sludge Effects on Soil Properties, Plant Growth, Mineral Nutrition State, and Heavy Metal Distribution in European Larch Seedlings (Larix decidua). Arabian Journal for Science and Engineering, Vol. 39, Iss. 7, pp. 5325-5335. http://dx.doi.org/10.1007/s13369-014-1100-0

2. Gradeckas, A., Kubertaviciene, L., Raguotis, A. 1995. Water sludge - for nurseries fertilization. Musu girios 2, p. 13-14. (In Lithuanian).

3. Gradeckas, A. 1993. Sewage sludge - the fertilizer for forest plantations. Musu girios 2, p. 13-14 (In Lithuanian).

4. Janeliauskiene, D. 1998. Sludge - the fertilizer free of charge. Gamta 7, 33 [in Lithuanian].

5. Lithuanian Statistical Yearbook of Forestry. 2014. Available at: http://www.amvmt.lt/images/veikla/stat/miskustatistika/2014/05\%20Misku\%20ukio\%20statistika\%202014_m.pdf (accessed on 10/09/2015)

6. Kucinskas, J., Pekarskas, J., Pranskietiene, I., Vaisvila, Z., Zemaitis, A. 1999. Agrochemistry, Kaunas: Lutute, 336 p. (In Lithuanian).

7. Osman, K., T. 2013. Forest Soil Management and Silvicultural Treatments. Forest Soils, pp. 183-210.

8. Racinskas, J. 2008. Forest seedling growth, Akademija, 11p. (In Lithuanian).

9. Racinskas, J., Kondratas, K., Silingiene, G. 2013. The influence of sewage sludge on Norway spruce seedlings. Zemes ukio mokslai, Vol. 20, iss. 1, p. 48-56. (In Lithuanian).

10. Skov, J. 1996. Handbook of forest nurseries for Lithuania, Kaunas. (In Lithuanian).

11. Slapakauskas, V. A. 2006. Plants ecophysiology, Kaunas: Lutute, 416 p. (In Lithuanian). 